\title{
DIABETIC FOOT ULCERS;
}

A COMPARISON OF OUTCOME OF VACUUM ASSISTED CLOSURE (VAC) DRESSING WITH WET DRESSINGS IN MANAGEMENT OF DIABETIC FOOT ULCERS.

1. FCPS Surgery, Assistant Professor Department of Surgery ABWA Medical College Faisalabad.

2. FCPS Medicine

Assistant Professor Department of Medicine ABWA Medical College Faisalabad.

3. MBBS,

Demonstrator

Department of Anatomy Independent Medical College

Faisalabad

Correspondence Address:

Dr. Sohail Farooq

142-Shadman Town Sargodha Road,

Faisalabad.

sohailfarooqdr@hotmail.com

Article received on:

11/06/2018

Accepted for publication:

$15 / 11 / 2018$

Received after proof reading:

$31 / 01 / 2019$

\section{Sohail Farooq ${ }^{1}$, Shaukat Javed ${ }^{2}$, Nazish Jahan ${ }^{3}$}

ABSTRACT... Introduction: Traditionally, moist dressings are being in used routinely by surgeons for management of diabetic foot ulcers. Recently, there is an encouraging trend of using VAC dressings in such patients. This study aimed to compare the outcome of VAC with moist dressing for management of diabetic foot ulcer. Study Design: Prospective randomized controlled trial. Setting: Department of Surgery, Al-Bukyriah General Hospital, Al-Bukayriah, Alqaseem KSA. Period: June 2012 to 07 December 2016. Methods and Material: 200 patients with diabetic foot ulcers. The patients were divided in two equal groups containing 100 patients each. In group A, 100 patients received VAC dressing treatment while in group B, 100 patients received wet dressings. Wound size, \% reduction in wound size, appearance of granulation tissue and fate of wound were main outcome measured which were noted at start of study and at the end of study ( $4^{\text {th }}$ week of therapy). Results: In group A, there were $73(73 \%)$ men and $27(27 \%)$ women with a mean age of $54.98 \pm 7.68$ years and in group $B$, there were there were $75(75 \%)$ men and $25(25 \%)$ women with a mean age of $55.23 \pm 6.98$ years. Size of wound before treatment in group A was $14.23 \pm 6.78 \mathrm{~cm} 2$ which reduced to $5.11 \pm 1.91 \mathrm{~cm} 2$ at $4^{\text {th }}$ wee and in group B it was $14.41 \pm 5.93 \mathrm{~cm} 2$ in the start which reduced to $11.29 \pm 3.63 \mathrm{~cm} 2$ at $4^{\text {th }}$ week $(p<0.05)$. Mean \%reduction in wound size in group A was 63.22 \pm 9.19 and $22.92 \pm 7.18$ in group $B(p<0.05)$. In group A, $43(43 \%)$ wounds healed spontaneously with shrinkage and group B only $2(2 \%)$ healed spontaneously $(p<0.05)$. Conclusions: VAC therapy is superior to moist dressing in terms of achieving early granulation tissue, reduction in wound size and spontaneous wound shrinkage.

Key words: $\quad$ Vacuum Assisted Closure; VAC; Wet Dressing; Outcome; Wound Size.

Article Citation: Farooq S, Javed S, Jahan N. A comparison of outcome of vacuum assisted closure (VAC) dressing with wet dressings in management of diabetic foot ulcers. Professional Med J 2019; 26(2):324-329.

DOI: $10.29309 / T P M J / 2019.26 .02 .3116$

\section{INTRODUCTION}

Diabetes mellitus is a chronic systemic metabolic ailment that is the consequence of disparity in production or consumption of insulin; a hormone that regulates sugar level in blood. ${ }^{1}$ According to data generated by World Health Organization in 2016, approximately 422 million people are recognized with diabetes mellitus and the number is progressively snowballing i.e anticipated upsurge in diabetes mellitus is $60 \%$ in next two decades in the United States. ${ }^{2,3}$ Diabetes mellitus is single-handedly accountable for 1.6 million deaths approximately. ${ }^{4}$ It can lead to grave morbidity e.g kidney, heart and blood vessels diseases. It can be reason of blindness and foot ulcers; termed as diabetic foot ulcer. Diabetic foot ulcer is a commonest, costly and devastating complication of uncontrolled diabetes mellitus that drags patient towards amputation of limb. ${ }^{5}$ The incidence of diabetic foot ulcer is $6.3 \%$ worldwide and it is more in men $(4.5 \%)$ as compared to women (3.5\%). ${ }^{6}$ It amplified the admission rate upto 11 fold in last 5 years. ${ }^{7}$ The rate of lower limb amputation due to diabetic foot ulcer is $67 \%$ in United States. This account $96 \%$ minor and $83 \%$ major amputations. ${ }^{8}$ Health care cost is more than 1 billion per year on diabetic foot ulcer management. ${ }^{9}$

Diabetic foot ulcer is product of amalgamation of neuropathy, atherosclerotic blood vessels and infection. It rises rate of hospital admission and duration of hospital stay. Its management is based on wound and foot care. After debridement, a 
moist gauze dressing can offer a healthy medium for the wound to heal e.g normal saline soaked gauze dressing or duoderm. However, moist gauze dressing is not suggested for all stages of healing ulcer e.g hydrogel dressings are good for necrotic foot ulcers. ${ }^{10}$

Moist gauze dressings (wet to dry saline soaked dressings) are simple, cost effective, have good patient compliance, easy to do and convenient. ${ }^{11}$ However, change of dressing is required frequently to keep the wound environment moist. Now a days, negative pressure wound therapy (NPWT) is utilized to aid in healing of diabetic foot ulcer. This therapeutic technique delivers negative pressure at wound area by creating a vacuum with use of vacuum assisted closure system that helps to remove slough and bacteria, enhance granulation tissue formation and draw the edges of wound closer. The drawbacks that this system carry are poor patient compliance and need hospitalization to achieve desired results of negative pressure wound therapy. Like moist gauze dressing, the negative pressure wound therapy is not advisable to all kinds of diabetic wounds and it will be only helpful after surgical removal of dead necrotic tissue from wound. So, surgically treated infected diabetic foot ulcer is exposed to either moist gauze dressing or negative pressure wound therapy for complete healing. ${ }^{12}$

The purpose of this study was to compare the rate of wound healing with the negative pressure wound therapy to conventional moist dressings in the treatment of large diabetic foot wounds.

\section{MATERIAL AND METHODS}

This prospective randomized controlled trial was conducted in the Department of Surgery, from June 2012 to 07 Dec 2016 after approval from ethical committee which included 200 diabetic patients with ulcers (Class I and II on Wagner's classification) over any part of foot and leg of any size $>2 \mathrm{~cm}$ and present for more than 6 weeks.

\section{Wagner Ulcer Classification System}

Grade 0- No open lesions; may have deformity or cellulitis
Grade 1- Superficial diabetic ulcer (partial or full thickness)

Grade 2- Ulcer extension to ligament, tendon, joint capsule, or deep fascia without abscess or osteomyelitis

Grade 3- Deep ulcer with abscess, osteomyelitis, or joint sepsis

Grade 4- Gangrene localized to portion of forefoot or heel

Grade 5- Extensive gangrenous involvement of the entire foot

We excluded all the patients below 18 years of age, acute ulcers, ulcers associated with osteomyelitis. Patients with urinary tract infection, urinary tract infection or on immunosuppression or steroid therapy, malignancy or in intensive care unit were also excluded. Demographic, history and physical examination were noted. The patients were randomly allocated in two groups based on lottery method. One hundred patients in group A had VAC (vacuum assisted closure) dressing applied after wound debridement, while 100 patients in group $B$ had moist dressing with hydrocolloid gel. Drain was attached to a negative pressure system that provides negative pressure of $125 \mathrm{mmHg}$ at intermittent interval. VAC dressing and hydrocolloid gel dressing were changed at every $3^{\text {rd }}$ day with wound examination weekly. The wound size was measured by ruler (length $X$ width in $\mathrm{cm}$ ) on the admission and at the end of fourth week. The result was categorized as percentage reduction of wound size by following formula; Surface area (length $X$ width in $\mathrm{cm}$ ) on admission - surface area (length $x$ width in $\mathrm{cm}$ ) at 4weeks/ surface area on admission= percentage reduction of wound size. The data was entered into SPSS version 20, computer program and analyzed accordingly. Study variables were analysed by simple descriptive statistics. Mean and standard deviation were calculated for numerical variables (age, height, BMI, fasting Blood sugar level, wound size and percentage reduction of wound size). Frequency and percentage were calculated for gender.

\section{RESULTS}

Clinical characteristics of patients and diabetic wounds are shown in Table-l. The male to female 
ratio were 2.7:1 in group $A$ and $3: 1$ in group $B$. the age and sex both were not statistically significant. Mean percentage decrease in the size of the wound after completion of therapy were 63.22 \pm 9.19 and $22.92 \pm 7.18$ in group $A$ and $B$, respectively and it is statistically significant. Diabetic Wound assessment features and fate of diabetic wounds are shown in Table-II and III.

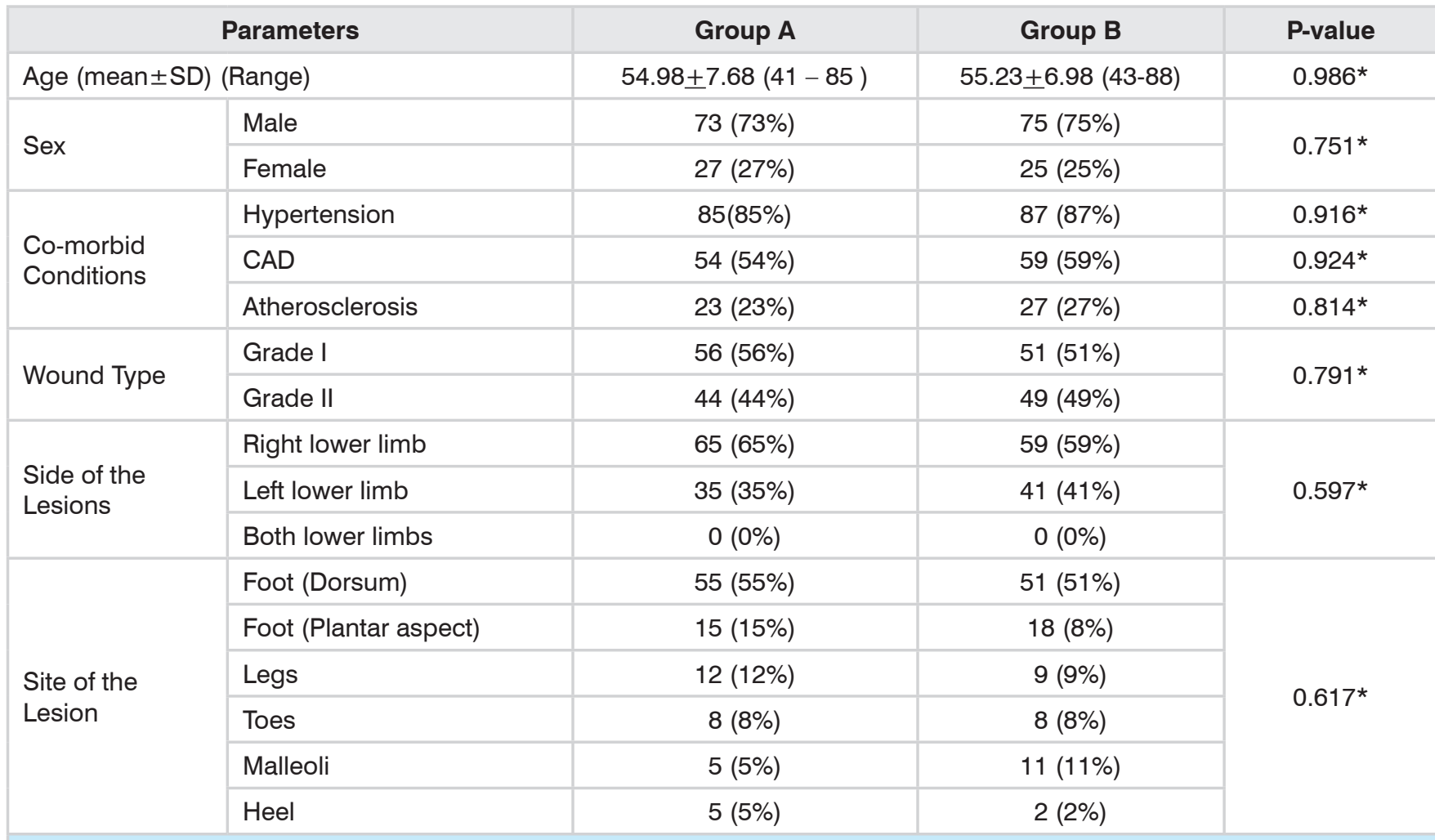

Table-I. Clinical characteristics of patents and diabetic wounds

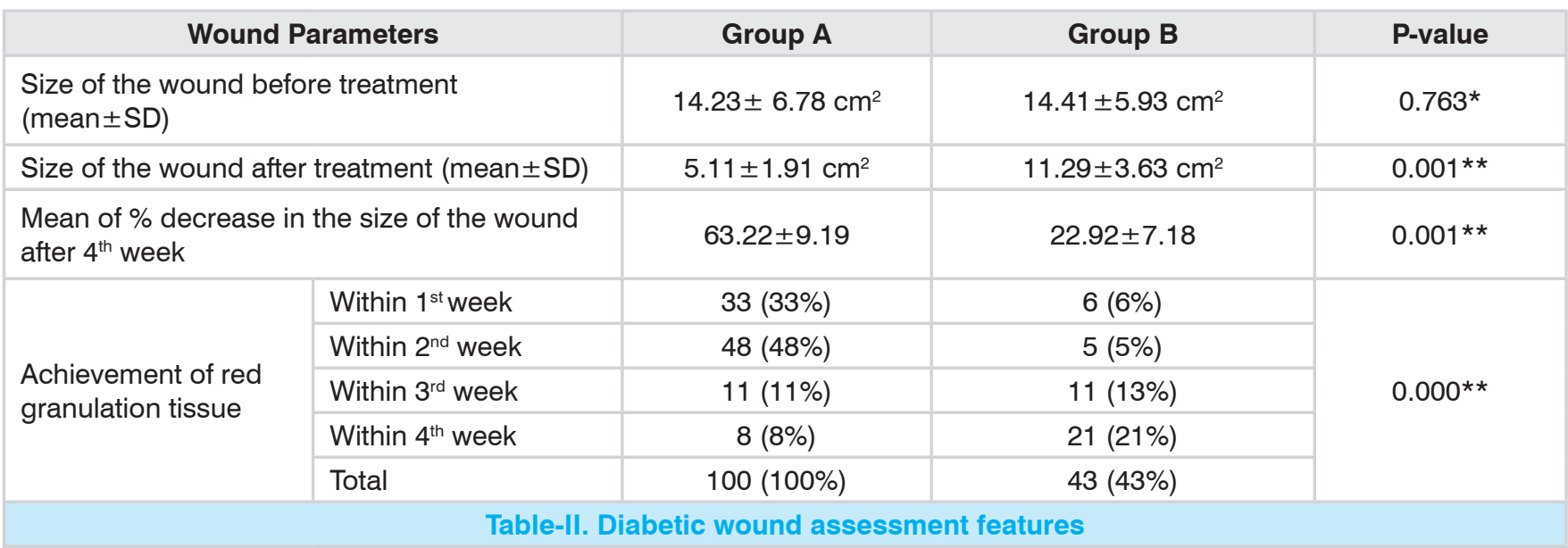

\begin{tabular}{|l|c|c|c|}
\hline \multicolumn{1}{|c|}{ Fate of Wound } & Group A & Group B & P-value \\
\hline Closure of wound with shrinkage & $43 \%$ & $2 \%$ & 0.001 \\
\hline Need for Skin grafting & $57 \%$ & $98 \%$ & 0.015 \\
\hline Amputations & & 0 & 0 \\
\hline
\end{tabular}




\section{DISCUSSION}

This was one of the largest clinical trial conducted on the VAC dressings which included 200 patients. Demographic characteristics were observed. The mean age of patients in our study was $54.98+7.68(41-85)$ years in group $A$ and $55.23+6.98(43-88)$ years in group $B$. There was no statistical significance in age groups $(p=0.986)$. When compared to other studies, we observe that mean age of patients in a study by Nain PS et al, in Group A was $61.33 \pm 7.63$ years and in Group B was $55.40 \pm 11.54$ years. ${ }^{13}$ In a prospective randomized control trial by Dsouza $\mathrm{C}$ et al, the mean age of patients in group $\mathrm{A}$ was 58.5 (34-90) and in group B was 58 (35-82) years and it is comparable to our study. ${ }^{14}$ However, in a study by Kajagar BM and Joshi $\mathrm{K}$, the mean age of patients in both groups was much lower than the mean age in our study i.e 35.7 and 35.4 years in group $A$ and $B$ respectively $(p=0.184) .{ }^{15}$ So, there was a great diversity among the age groups of the patients among different authors. In our study, male population dominated over female. There were $73 \%$ male and $27 \%$ females in group $A$ and $75 \%$ male and $25 \%$ females in group B in our study. The male to female ratio were 2.7:1 in group A and 3:1 in group B. Similarly, in a study by Nain PS et al, the male predominance was observed i.e $80 \%$ males whereas $20 \%$ females in Group A, while in Group B, 86.67\% males and $13.33 \%$ were females. ${ }^{13}$ In another study by Dsouza $C$ et al, the sex distribution was similar to our study i.e $76.7 \%$ male and $23.3 \%$ females in group $A(M: F ; 2.3: 1)$ and $70 \%$ males and $30 \%$ females in group $B(M: F ; 1: 3.2) .{ }^{14}$ In a prospective comparative study by Rajenderan AK et al, male to female ratio was $16: 4$ in both groups and it is higher than ratio observed in our study. ${ }^{16}$ In all these studies, in both groups, there is male predominance observed however, in a study by Kajagar BM and Joshi K, the female predominance was found in group $A(M: F ; 1: 1.14)$ while in group $B$ male predominance was seen $(M ; F ; 1.5: 1)$ and there were no statistical significance was found $(p=0.301) \cdot{ }^{15}$

The hypertension, coronary artery disease and atherosclerosis were seen in $85 \%, 54 \%$ and $23 \%$ patients in group $A$ and $87 \%, 59 \%$ and $27 \%$ patients in group $B$ respectively. The comorbid conditions (hypertension, CAD and atherosclerosis) were statistically studied and found comparable with no significant difference between two groups $(p=0.916,0.924$ and 0.814 respectively). However, in a study by Dsouza $\mathrm{C}$ et al, hypertension was seen in less number of patients as compared to our study i.e $30 \%$ and $46.7 \%$ patients in group $A$ and group $B$, respectively. ${ }^{14}$ So, it can be observed that comorbid conditions grossly vary among different authors.

Wagner Grade I and II diabetic foot ulcers were seen in $56 \%$ and $44 \%$ patients in group $A$ and $51 \%$ and $49 \%$ patients in group B respectively $(p=0.791)$. However, in a study by Nather A et al, Wagner Grade II and III were seen in $27.27 \%$ and $72.7 \%$ respectively. ${ }^{17}$

Diabetic foot ulcers were found on right and left lower limbs in $65 \%$ and $35 \%$ patients in group A and $59 \%$ and $41 \%$ patients in group $B$ respectively $(p=0.597)$. None of the patient was found with diabetic foot ulcer on both lower limbs in our study. Sites of diabetic foot ulcers were dorsum and planter surfaces of foot in 55\% and $15 \%$ patients in group $A$ and $51 \%$ and $8 \%$ patients in group $B$ respectively in our study. While in the study by Dsouza $\mathrm{C}$ et al, the foot was the site of lesion in $20 \%$ and $36.7 \%$ patients in group $A$ and group $B$ respectively. ${ }^{14}$

In our study, there was a significant shrinkage in the size of wound in VAC dressing group i.e. from $14.23 \pm 6.78 \mathrm{~cm}^{2}$ to $5.11 \pm 1.91 \mathrm{~cm}^{2}$. This was an encouraging observation, which shows that VAC dressing is helpful in reducing the size of wound and $14.41 \pm 5.93 \mathrm{~cm}^{2} \mathrm{~cm}$ respectively and there is no statistical significance $(p=0.763)$. The mean sizes of the wound after negative pressure wound therapy and conventional saline dressing were and $11.29 \pm 3.63 \mathrm{~cm}^{2}$ respectively and it is statistically significant $(p=0.001)$. In a study by Nain PS et al, the mean decrease in the wound size in patients of Group A was $-16.14 \pm 13.04 \mathrm{~cm}^{2}$ and that of Group B was $-5.98 \pm 14.41 \mathrm{~cm}^{2,13}$ VAC dressing is helpful in generating some mechanical dynamics on the tissue growth by means of migration of 
cells and process of mitosis. Increasing blood flow and decreases tissue edema.

A mainstay of treatment is reduction in size of the wound. We observed a significant decrease in wound surface area. The average percentage reduction in wound area treated with negative pressure wound therapy was $24.9 \%$ (Range $9.6 \%$ $-65.1 \%, P>0.05)$ in a study by Nather A et al. ${ }^{17}$

In our study, the red granulation tissue is seen in $100 \%$ of wounds that treated with negative pressure wound therapy while it is seen only in $43 \%$ wounds those treated with conventional saline dressings. In group $A$, the maximum number of wounds i.e $48 \%$ wounds, showed healthy granulation tissue within 2 nd week of treatment followed by $33 \%$ within 1st week, $11 \%$ within 3 rd week and $8 \%$ within 4 th week of treatment. However, in group B, maximum number of wounds i.e $21 \%$ wounds, showed red granulation tissue within 4th week of treatment with conventional saline dressings followed by $13 \%$ within 3 rd week, $6 \%$ within 1 st week and $5 \%$ wounds within 2 nd week of treatment. The granulation tissue was seen in all wounds treated with negative pressure wound therapy and there is prompt presence of granulation tissue in these wounds as compared to wounds treated with saline soaked conventional dressings. Similarly, in a study by Nain PS et al, granulation tissue at 2 nd week of treatment was seen in $75 \%$ and $30 \%$ wounds with negative pressure wound therapy and saline dressing, respectively. ${ }^{13}$ In another study by Dsouza C et al, $76.7 \%$ and $46.7 \%$ of wounds had red granulation tissue at the end of 6th week in group $A$ and $B$ respectively. ${ }^{14}$ Achieving granulation tissue in diabetic foot is very demanding job. Once granulation is established, it can be used for skin grafting etc.

In our study, spontaneous closure of wounds were frequently observed (43\%) in group A while it was seen in only $2 \%$ patients in group $B$. However, in a study by Nain PS et al, the spontaneous closure of wounds were observed in $60 \%$ and $20 \%$ wounds in group $A$ and $B$ respectively, which is higher than in our study. ${ }^{13}$ In our study, Skin grafting to close wounds was required in $57 \%$ and $98 \%$ patients of group A and B respectively $(p=0.015)$. None of the patient underwent amputation in both groups in our study. In study by Rajenderan AK et al, spontaneous wound closure were observed in $45 \%$ of wounds while skin grafting was required in $55 \%$ wounds treated with negative pressure wound therapy. ${ }^{16}$

Using VAC dressing has shown promising results. But, its cost is a limitation in its use. The study has certain limitations. It was a single center study based on experience of single surgeon. Moreover, this was not a double blind study.

\section{CONCLUSION}

Wounds treated with VAC therapy achieve granulation tissue earlier, more reduction in wound size and more spontaneous closure of wound as compared to wounds treated with saline conventional dressings. VAC dressing should be preferred over wet dressing in diabetic foot ulcers.

\section{Copyright (C) 15 Nov, 2018.}

\section{REFERENCES}

1. Boulton AJ, Vileikyte L, Ragnarson-Tennvall G, Apelqvist J. The global burden of diabetic foot disease. The Lancet 2005; 366(9498):1719-24.

2. Steed DL, Donohoe D, Webster MW, Lindsley L. Effect of extensive debridement and treatment on the healing of diabetic foot ulcers. Diabetic Ulcer Study Group. J Am Coll Surg 1996; 183(1):61-4.

3. Jeffcoate WJ, Vileikyte L, Boyko EJ, Armstrong DG, Boulton AJ. Current challenges and opportunities in the prevention and management of diabetic foot ulcers. Diabetes care 2018; 41(4):645-52.

4. Hingorani A, LaMuraglia GM, Henke P, Meissner $\mathrm{MH}$, Loretz L, Zinszer KM, Driver VR, Frykberg R, Carman TL, Marston W, Mills JL. The management of diabetic foot: A clinical practice guideline by the Society for Vascular Surgery in collaboration with the American Podiatric Medical Association and the Society for Vascular Medicine. J Vasc Surg 2016; 63(2):3S-21S.

5. Kumar B, Mishra MK, Sinha A, Soni RK, Patel DK. Prospective study to correlate the level of glycosylated haemoglobin with wound healing, vasculopathy and neuropathy in diabetic foot patients. Int J Surg 2016; 3(4):2087-91.

6. Rice JB, Desai U, Cummings AK, Birnbaum HG, 
Skornicki M, Parsons NB. Burden of diabetic foot ulcers for medicare and private insurers. Diabetes care $2014 ; 37(3): 651-8$.

7. Lipsky BA, Apelqvist J, Bakker K, Van Netten JJ, Schaper NC. Diabetic foot disease: Moving from roadmap to journey. Lancet Diabetes Endocrinol 2015; 3(9):674-5.

8. Lavery LA, Fulmer J, Shebetka KA, Regulski M, Vayser D, Fried D, Kashefsky H, Owings TM, Nadarajah J, Grafix Diabetic Foot Ulcer Study Group. The efficacy and safety of Grafix ${ }^{\circledR}$ for the treatment of chronic diabetic foot ulcers: results of a multi $\square$ centre, controlled, randomised, blinded, clinical trial. Int Wound J 2014; 11 (5):554-60.

9. Crews RT, Schneider KL, Yalla SV, Reeves ND, Vileikyte $\mathrm{L}$. Physiological and psychological challenges of increasing physical activity and exercise in patients at risk of diabetic foot ulcers: A critical review. Diabetes Metab Res Rev 2016; 32(8):791-804.

10. Faglia E, Clerici G, Frykberg R, Caminiti M, Curci V, Cetta F, Prisco V, Greco R, Prisco M, Morabito A. Outcomes of chopart amputation in a tertiary referral diabetic foot clinic: Data from a consecutive series of 83 hospitalized patients. J Foot Ankle Surg 2016; 55(2):230-4.

11. Armstrong DG, Boulton AJ, Bus SA. Diabetic foot ulcers and their recurrence. N Engl J Med 2017; 376(24):2367-75.
12. Asten SA, Nichols A, Fontaine J, Bhavan K, Peters EJ, Lavery $L A$. The value of inflammatory markers to diagnose and monitor diabetic foot osteomyelitis. Int Wound J 2017; 14(1):40-5.

13. Nain PS, Uppal SK, Garg R, Bajaj K, Garg S. Role of negative pressure wound therapy in healing of diabetic foot ulcers. J Surg Tech Case Rep 2011; 3(1):17-22.

14. Dsouza C, Diaz E, Rao S. A randomized controlled trial comparing low cost vacuum assisted dressings and conventional dressing methods in the management of diabetic foot ulcers. Int J Surg 2017; 4(12):3858-65.

15. Kajagar BM, Joshi K. Efficacy of vacuum-assisted closure therapy versus conventional povidone lodine dressing in the management of diabetic foot ulcers: A randomized control trial. Int J Health Sci Res 2017; 7(5): 47-51.

16. Rajenderan AK, Babu A, Kumaresan RC, Sezhian G. Comparison of efficacy of negative pressure wound therapy VS conventional normal saline dressing in diabetic foot. SMJ 2018; 4(4):9-12.

17. Nather A, Chionh SB, Han AY, Chan PP, Nambiar A. Effectiveness of vacuum-assisted closure (VAC) therapy in the healing of chronic diabetic foot ulcers. AAMS 2010; 39(5): 353-8.

\section{Worrying does not take away tomorrow's troubles, it takes away today's peace.}

“Unknown"

\section{AUTHORSHIP AND CONTRIBUTION DECLARATION}

\begin{tabular}{|c|l|l|l|}
\hline Sr. \# & \multicolumn{1}{|c|}{ Author-s Full Name } & \multicolumn{1}{|c|}{ Contribution to the paper } & Author=s Signature \\
\hline 1 & Sohail Farooq & $\begin{array}{l}\text { Study, Writing, Patient } \\
\text { managemnet. } \\
\text { Study, Patient management. }\end{array}$ \\
\hline 3 & Shaukat Javed & Sazish Jahan & Study, patient management.
\end{tabular}

